\title{
Культурная идентичность в процессе русско-польского перевода
}

\author{
Cultural identity in the process \\ of Russian-Polish translation
}

\begin{abstract}
The article deals with the issue of transferring intertextual cultural elements in the process of translation from Russian into Polish. The material for analysis is the fragments of the novel The Black City by Boris Akunin and its translation into Polish by Aleksandra Okuniewska-Stronka. The aim of this article is to present and evaluate the results of transferring cultural connotations and intertextual references from one culture to another. Cultural elements play a significant role in the process of the reception of the text and its translation both by the readers of the original text - native language users - and by the recipients of the translated variant, belonging to a different culture. The comparison of source units and translated target units shows how different the associative circles arising in the process of text reception are. The analysis leads to the conclusion that taking into account the associative and intertextual potential of language units in translation is a very complex process. It requires a double cultural competence from the translator, and involves not only the interpretation of language signs in terms of their cultural code, but also the assessment of the interpretative abilities and capabilities of the recipients.
\end{abstract}

Keywords: intertextual references, cultural connotation, translator's decisions, The Black City, Boris Akunin

Jolanta Jóźwiak, Uniwersytet Kazimierza Wielkiego, Bydgoszcz - Polska, e-mail: jjozwiak@ poczta.onet.pl, ORCID ID: https://orcid.org/0000-0003-0884-821X

Проблема передачи культурных ценностей в процессе перевода непосредственно связана с культурной коннотацией языковых элементов оригинала, которую по мере возможности переводчики стараются сохранить в переводческих вариантах. Однако пути решения этого вопроса бывают различными по разным причинам.

Вероника Николаевна Телия определяет коннотацию как „любой прагматически ориентированный компонент плана содержания языковых сущностей (морфем, слов, фразеологизмов и отрезков текста), который дополняет 
денотативное и грамматическое их содержание". По словам исследовательницы, содержание единиц может дополняться на основе сведений, соотносимых с прагматическими факторами разного рода: с ассоциативно-фоновым (эмпирическим, культурно-историческим, мировоззренческим и т. п.) знанием говорящих на данном языке о свойствах или проявлениях обозначаемой реалии или ситуации, с рационально-оценочным или эмоционально-оценочным (эмотивным) отношением говорящего к обозначаемому, со стилистическими регистрами, характеризующими условия речи или сферу языковой деятельности, социальные отношения между участниками речи, еe формы и т. п. (Teliâ 107).

Следует напомнить, что анализируя исходные единицы оригинала, иногда трудно отделить один прагматический фактор от другого, потому что они, как правило, связаны друг с другом. В процессе передачи подобного рода элементов переводчик определяет иерархическую важность смысловых компонентов, на этой основе принимает решения, и в результате возможно появление разных соответствий.

Цель настоящего анализа заключается в представлении результатов передачи элементов, обладающих культурно-национальной коннотацией, и оценке возможности, а также обоснованности сохранения культурных ценностей в процессе трансфера текста из одной культуры в другую. Иллюстративным материалом послужит роман представителя современной русской литературы Бориса Акунина Черный город из фандоринского цикла и созданный Александрой Окуневской-Стронкой перевод текста на польский язык Czarne miasto.

Культурная коннотация определяется Телия как интерпретация денотативного или образно мотивированного аспекта значения в категориях культуры (Teliâ 107). Хотя термин появился в исследованиях, касающихся фразеологических единиц, его можно отнести к любым единицам, связанным тем или иным образом с культурными кодами. Как отмечает Валентина Авраамовна Маслова, „именно культурная коннотация придает культурно-значимую маркированность не только значениям фразеологических единиц, символам или метафорам, но и смыслу всего текста, в котором они употребляются" (Maslova 56). Приведенное замечание очень важно с перспективы переводчика, поскольку из него следует, что единицы рассматриваемого характера сильно влияют на формирование смысла текста. Конечно, ряд таких единиц можно продолжить. В настоящей статье внимание сосредоточивается на именах собственных различного характера.

Итак, заглавная культурная идентичность относится именно к способности элементов с культурно-национальной коннотацией актуализировать осознание культурной принадлежности слов и выражений читателями и та- 
ким же образом воспринимать их в рамках оппозиции свой - чужой. Имена собственные появляются в литературных текстах в разных формах и контекстах. Следует отметить, что они часто имеют интертекстуальный характер. Именно поэтому переводчик вынужден быть очень внимательным при выборе соответствия и оценке интертекстуального потенциала читателей. На примере фрагмента романа Черный город и его перевода на польский язык проанализируем, какое количество информации культурного характера может содержаться в одном абзаце и в какой степени возможно сохранить весь культурный фон текста, ср.:

Фандорин искоса взглянул на Саадат. С ее лицом эффект пылающего моря проделал фокус еще более удивительный: госпожа Валидбекова превратилась в Царевну-Лебедь с известного полотна Врубеля. Залюбовавшись, Эраст Петрович чуть не влетел в самое пекло - едва успел повернуть штурвал (Akunin 2014a: 244).

Fandorin zerknął z ukosa na Saadat. Z jej twarzą efekt płonącego morza zrobił jeszcze bardziej zadziwiającą sztuczkę. Pani Walidbekowa zamieniła się w Carewnę Łabędzia ze znanego płótna Wrubla. Zapatrzywszy się, Erast Pietrowicz omal nie wpadł w samo piekło, ledwie zdążył wymanewrować sterem (Akunin 2014b: 252).

С лингвистической перспективы в приведенном фрагменте передача имен собственных нуждалась в принятии переводчиком двух рекомендуемых в подобных случаях решений. Имя и фамилия владелицы бакинских нефтяных вышек Саaдат Валидбекова передано транскрибированной записью, что позволяет читателям почувствовать чуждость антропонима, однако не затрудняет его прочтение. Имя и фамилия являются элементами культурного фона и соотносятся с местом действия романа - Баку. В свою очередь фамилия известного русского художника Михаила Алексанровича Врубеля передана с помощью установленного варианта.

С наименованием Царевна-Лебедь дело намного сложнее. Первоисточником рассматриваемого интертекстуального элемента является произведение А. С. Пушкина Сказка о изаре Салтане, о сыне его славном и могучем богатыре князе Гвидоне Салтановиче и о прекрасной цуаревне Лебеди, которая польской аудитории известна под заглавием Bajka o carze Sattanie, o jego synu, sławnym i potężnym bohaterze, księciu Gwidonie Sałtanowiczu i o pięknej księżniczce Łabędzicy ${ }^{1}$. Однако представленное в приведенном фрагменте сравнение, служащее характеристикой Саадат и в какой-то степени предсказывающее развитие ее отношений с Фандориным в будущем, относится не

${ }^{1}$ Следует отметить, что соответствие księżniczka Łabędzica употребляется во всех трех имеющихся в польском языке переводах Яна Бжехвы, Анджея Левандовского и Болеслава Лондонского. 
столько к волшебному сказочному образу царевны Лебеди, сколько к художественному воплощению героини сказки, придуманному и представленному Михаилом Врубелем на известной картине. Сравнение Саадат с фольклорным образом царевны Лебеди имеет своей целью указать на два начала - светлое и темное, на сочетание несочетаемого. Именно такие две тенденции истолкования женских образов выделялись в символизме: „[...] с одной стороны, женщину идеализировали, изображая ее целомудренной, чистой, глубоко религиозной, далекой, с другой - в произведениях создавался образ женщины развратной, проклятой, увлекающей мужчину на путь порока и падения" (Erohina 212).

Неслучайно события происходят на фоне горящего (подожженного) моря, т. е. пожара нефти на поверхности воды, вследствие чего создается невообразимое, одновременно жуткое и захватывающее зрелище. А множество возникающих оттенков пламени также сравнивается в сознании компетентных читателей с цветовой гаммой представленного на картине Врубеля многообразия тончайших оттенков белого в момент превращения царевны в птицу. Это возможно, конечно, только в случае, если этот образ был раньше запечатлен в памяти читателя. Приведенный иллюстративный материал можно считать реализацией того, о чем писала Наталья Арнольдовна Кузьмина о цитатах в широком смысле, называя цитату интертекстуальным знаком „с высоким энергетическим потенциалом, позволяющим ему продвигаться во времени и в пространстве интертекста, накапливая культурные смыслы и тем увеличивая имплицитную энергию" (Kuz'mina 99).

Как следует из рассмативаемого отрывка, в тексте польского варианта романа переводчик воспользовался соответствием Carewna Łabędź. В польском языке название картины Врубеля действительно закрепилось именно в такой форме. В свою очередь, название Księżniczka Łabędzi является заглавием американского мультфильма для детей - мотив девы-лебеди известен во многих культурах. Следует упомянуть, что в русском языке названию мультфильма соответствует Принцесса Лебедь, то есть в языково-культурном плане сохраняются отличия между царевной и принцессой. В польском переводе фрагмента Черного города культурную маркированность обеспечивает применение слова carewna вместо księżniczka. Надо еще раз подчеркнуть, что в переводе заглавия сказки Пушкина закрепилось слово księżnicz$k a$, а в переводе заглавия картины Врубеля - слово carewna, в результате чего переводчик вынужден был принять соответствующее решение.

Следует также отметить, что в рассматриваемой ситуации интертекстуальность переплетается в сознании русскоязычных реципиентов как бы на двух уровнях: на уровне сказки и на уровне картины, являющейся художественно-творческой интерпретацией упомянутого произведения. Обе 
формы: сказка и картина - живы в сознании читателей оригинала, и эта актуальность несравнима с возможностями по созданию подобного круга ассоциаций у представителей других культур, в том числе и в польской аудитории - что важно - независимо от использованной переводчиком формы соответствия.

В следующем фрагменте романа и его переводе имеются два иных антропонима с культурной коннотацией, ср.:

Диалог с изображаемым чертякой давно вошел у него в привычку. Это помогало отфильтровать мысли.

Психически человек был абсолютно здоров, шизофренией не страдал, внутренними раздорами не терзался, к образу Ивана Карамазова и творчеству Федора Достоевского относился юмористически. Но идея разговора с умным, едким, критически настроенным оппонентом была продуктивной. Всегда полезно подвергнуть свои взгляды и планы испытанию скепсисом. В дьявола, как и в боженьку, человек, разумеется, не верил, однако к аллегории ангела-революционера, решившего свергнуть небесное самодержавие, относился с одобрением (Akunin 2014a: 91).

Dialog z wyimaginowanym biesem dawno wszedł mu w nawyk. Pomagało mu to przefiltrować myśli.

Psychicznie mężczyzna był absolutnie zdrowy, nie cierpiał na schizofrenię, nie dręczyło go wewnętrzne rozdarcie, do postaci Iwana Karamazowa i twórczości Fiodora Dostojewskiego podchodził z humorem. Ale pomysł rozmowy z mądrym, szyderczym, krytycznie nastawionym oponentem był produktywny. Zawsze warto poddać swoje poglądy i plany sceptycznej próbie. W diabła, jak i w Bozię, mężczyzna oczywiście nie wierzył, jednakże alegorię anioła-rewolucjonisty, który postanowił obalić niebiańską hierarchię, traktował z aprobatą (Akunin 2014b: 94-95).

Цитаты-имена авторов и героев произведений, в данном случае Федор Достоевский и Иван Карамазов, являются наименее сложными для идентификации. Подобного рода формы, т. е. тематические ссылки ономастического характера, Анна Майкевич причисляет к эксплицитным показателям интертекстуальности (cp. Majkiewicz 23-25). Однако непосредственная ссылка на Братьев Карамазовых - получивший общемировую известность роман Федора Михайловича Достоевского - является только исходной точкой для возникновения более конкретного круга ассоциаций. Во фрагменте упоминается „диалог с изображаемым чертякой”, а в целом романе Акунина находится несколько длинных фрагментов текста с подзаголовком Разговор с чертом, выделенных даже особым шрифтом (в переводе выделение не сохранилось), в которых описывается разговор с чертом, вернее всего внутренний монолог революционера-большевика Дятла. Согласно классификации Майкевич, здесь имеется имплицитная ссылка интертекстуального характеpa, целью которой является актуализация образа Ивана Карамазова, в снах которого появляется черт, разрушающий равновесие в его душе. Такого рода 
ассоциация имеет уже не только общий, но более конкретный характер, а ономастические ссылки становятся инструментом перехода на следующий ассоциативный уровень.

Как следует из приведенного фрагмента, пример особо интересен с лингвистической перспективы. Изображаемый Дятлом оппонент в русском языке назван с помощью синонимического ряда черт, чертяка, дьявол, Лукавый, а среди польских соответствий встречаются слова bies, diabet и еще в ином месте czart. В вышеприведенном контексте слово bies вероятнее всего не случайно выбрано, так как помогает вызвать намеренные ассоциации с творчеством Достоевского, направляя мышление в сторону другого произведения писателя - романа, известного польским читателям под заглавием Biesy.

Очередное название воображаемого Дятлом оппонента в виде субстантивированного существительного Лукавый употреблено, по нашему мнению, не только как одно из синонимических наименований дьявола, но имеет также характер значащего имени, что позволяет сослаться на значение 'лживый, обманный, подлый, хитрый', указывая опосредованным образом на черты самого Дятла, ср.:

- Фи, как нескромно, - ответил Лукавый. - Но не спорю. Придумано ловко. Я все думал, как ты решишь эту загвоздку (Akunin 2014a: 263).

- Fe, cóż za brak skromności - odparł czart. - Ale nie będę się spierał. Sprytnie obmyślone. Zastanawiałem się tylko, jak rozwiążesz tę kwestię (Akunin 2014b: 272).

Следует отметить, что в польском переводе фрагмента не акцентируются черты характера из-за отсутствия субстантивированного существительного или другого варианта синонима с таким же значением.

Интертекстуальные ссылки в форме имен собственных должны рассматриваться переводчиком индивидуально еще и потому, что способность их идентификации может быть совсем разной, даже если они относятся, например, к одному и тому же историческому периоду или событию, ср.:

Торжественные мысли, заставлявшие сердце сжиматься, были вот какие. Елки зеленые! То самое, о чем мечтали тысячи героев, отдавших свои жизни ради невообразимо далекой цели, произойдет совсем скоро. И своротят махину не Степан Разин и не Пугачев, не Рылеев с Пестелем, не Желябов, не Плеханов. Это сделаешь ты. Не в одиночку, конечно. Но замысел твой. И реализация замысла тоже твоя (Akunin 2014a: 263).

Szczytne myśli zmuszające serce do większego wysiłku były następującej treści: Jasny gwint! To, o czym marzyły tysiące bohaterów, którzy oddali życie w imię wydumanego, odległego celu, nastąpi już niebawem. I machinę obalą nie Stiepan Razin czy Pugaczow, nie Rylejew z Piestielem, nie Żelabow ani Plechanow. Ty to zrobisz. Nie sam, oczywiście. Ale pomysł jest twój. I jego realizacja również (Akunin 2014b:271-272). 
Все имеющиеся в оригинале фамилии переданы в польском варианте с помощью переводческой транскрипции, однако их интертекстуальный потенциал в обоих языках не является одинаковым. Антропонимы вызывают несравнимые в любом плане ассоциации относительно отдельных фамилий в русскоязычной и польской аудиториях. Например, фамилия декабриста Рылеева более известна иностранным реципиентам, чем фамилия Пестеля, как и фамилия Плеханова по отношению к Желябову. Однако следует подчеркнуть, что в общем плане направление ассоциаций в сторону революции, восстания против власти достигается и в переводе, делая характеристику Дятла более образной. Рассматриваемые единицы являются т. н. потенциальными носителями чуждости и в зависимости от предыдущих знаний читателей способны вызвать у них чуждость общего или более конкретного характера (ср. Lewicki 45).

Следующее, безусловно, культурно наполненное наименование многократно выступающего в русском фольклоре фантастического существа появляется в Черном городе в высказывании друга Фандорина японца Масы для объяснения, почему в Баку женщины закрывают свои лица, ср.:

Бакинки в чадрах встретились им еще несколько раз, и каждый раз японец впивался в них взглядом.

- Должно быть, женщины в Ба-Ку очень умны, - наконец изрек он.

- С чего ты взял?

- Те, кто уродлив, предпочитают прятать лицо. Это ли не свидетельство ума? ...Но встречаются и глупые, - прибавил он минуту спустя. - Вон та тощая кикимора лучше бы завесилась тряпкой.

Русское слово кикимора вошло в речевой обиход Масы недавно - понравилось своей звучностью и японообразностью (Akunin 2014a: 54).

Приведенный фрагмент в переводе на польский язык получил нижеследующий облик, и дополнительно появилась не совсем удачная, поскольку не передавала надлежащим образом значение, сноска, ср.:

Bakijki w czadrach mijali jeszcze kilkakrotnie i za każdym razem Japończyk pożerał je wzrokiem.

- Kobiety w Ba-Ku są chyba bardzo mądre - orzekł w końcu.

- Skąd to przypuszczenie?

- Te szpetne wolą zakryć twarz. Czy to nie dowodzi rozumu?... Ale zdarzają się też głupie dodał minutę później. Na przykład tamta chuda kikimora powinna się zasłonić jakąś szmatką. Rosyjskie słowo kikimora weszło do słownika Masy niedawno - spodobało mu się dzięki swojej dźwięczności i podobieństwu do japońskiego (Akunin 2014b: 58)

* Kikimora (ros.) - poczwara (przyp. tłum.).

Подобного рода объяснение существенно ограничивает возможность возникновения предполагаемых автором ассоциаций. Слово кикимора от- 
носится к национально маркированной лексике, безэквивалентной лексике, а в его значении запечатлен предмет национальной культуры, фрагмент мифа. В восточнославянской мифологии рассматриваемое слово обозначало нечистую силу, злого духа дома в виде маленькой женщины-невидимки, иногда (из-за расплывчатости представлений) она считалась женой домового. В русском арго кикимора обозначает также злую, некрасивую женщину. По словарю Ушакова, слово употребляется также для названия человека нелепого или смешного вида, смешно одетого. Данная единица употребляется в разных контекстах для обозначения некоторых отрицательных черт, однако может выступать в качестве антропонима - прозвища. В диалогической реплике Масы упомянутая языковая единица служит как групповой характеристике женщин в чадрах, так и индивидуальной оценке конкретной женщины, причем при конкретизации учитываются здесь личные предпочтения японца. Следует отметить, что в фандоринском цикле романов присутствие Масы как персонажа, его восприятие окружающего мира и комментарии придают разным ситуациям иронично-комический характер. Такого эффекта помогают достигнуть национально-культурные различия, многократно обыгрываемые Акуниным.

Как было отмечено, для сохранения в переводческом варианте описываемого экзотирующего элемента применяется транскрипция. Однако в сноске, если она уже имеется в тексте перевода, должна была появиться более подробная, культурно весомая, фоновая информация, очевидная для русскоязычных получателей, но неизвестная представителям других культур, в том числе и польским реципиентам. В таком случае читатели могли бы получить более полное представление об одном из элементов русской культурно-национальной языковой картины мира. Следует отметить, что решение о наличии или отсутствии пополняющей знания сноски в каждом отдельном случае принадлежит переводчику. И именно переводчик решает, какой облик в тексте перевода получат единицы с культурной коннотацией, которые причисляются Романом Левицким к потенциальным носителям чуждости.

Как уже упоминалось, наделенные культурной коннотацией единицы часто имеют интертекстуальный характер, что связано с отсылкой потенциальных читателей к культурно-историческому наследию определенной языково-культурной общности. Как замечает Маслова,

в коннотации реализуются потенциальные ресурсы номинативной системы языка, ибо коннотативное слово обладает способностью не только создавать, но и удерживать глубинный смысл, находящийся в сложных отношениях с семантикой слова, закреплять его в языке, создавая тем самым культурно-национальную языковую картину (Maslova 56). 
Поэтому так существенны попытки раскрытия и передачи культурных коннотаций в переводах текстов на другие языки. Как замечает Тамара Анатольевна Казакова, восприятие художественной информации в большой степени зависит от „коллективного и частного опыта, оценок и предпочтений, сознательных и интуитивных реакций на меру выразительности языковых знаков, участвующих в построении вымышленного мира" (Kazakova 104).

В ходе анализа неоднократно подчеркивалась именно существенная роль элементов с культурно-национальной коннотацией в процессе восприятия текста и его интерпретации как читателями оригинала - носителями языка, так и реципиентами переводческого варианта из другого культурного круга. Передача подобного рода переводческих единиц с сохранением их ассоциативного и интертекстуального потенциала является сложной задачей и требует особого опыта и одаренности. Можно прийти к выводу, что для принятия решения о способе передачи переводчику необходима культурная компетенция, вернее всего, двойная культурная компетенция, позволяющая не только интерпретировать языковые знаки в категориях культурного кода, но также оценить интерпретационные способности/возможности реципиентов.

\section{Библиография}

Akunin, Boris. Černyj gorod. Moskva, „Zaharov”, 2014a.

Akunin, Borys. Czarne miasto. Per. Agnieszka Okuniewska-Stronka. Warszawa, Świat Książki, $2014 b$.

Erohina, Tat'âna Aleksandrovna. „Grani ženstvennosti v russkom simvolizme”. Aroslavskij pedagogičeskij vestnik, 6, 2015, s. 210-217.

Kazakova, Tamara. Hudožestvennyj perevod: v poiskah istiny. Sankt-Peterburg, Izdatel'stvo Sankt-Peterburgskogo universiteta, 2006.

Kuz'mina, Natal'â. Intertekst i ego rol'v processah èvolûcii poètičeskogo âzyka. Moskva, Knižnyj dom „Librokom”, 2017.

Lewicki, Roman. Obcość w odbiorze przekładu. Lublin, Wydawnictwo UMCS, 2000.

Majkiewicz, Anna. Intertekstualność - implikacje dla teorii przektadu. Warszawa, Wydawnictwo Naukowe PWN, 2008.

Maslova, Valentina. Lingvokul'turologiâ. Moskva, Izdatel'skij centr Akademiâ, 2007.

Teliâ, Veronika. Russkâ̂ frazeologiâ. Semantičeskij, pragmatičeskij i lingvokul'turologičeskij aspekty. Moskva, Izdatel'skij dom „Âzyki slavânskoj kul'tury”, 1996. 
